\title{
A holistic approach to campus well-being: Steps to Leaps at Purdue University
}

\author{
Beth McCuskey ${ }^{1}\left[\right.$ · Fanyi Zhang ${ }^{2}\left({ }^{\circ}\right.$
}

Received: 27 April 2021 / Accepted: 16 August 2021 / Published online: 25 November 2021

(c) The Author(s), under exclusive licence to Springer Nature Switzerland AG 2021

\begin{abstract}
In response to the increasing demand of mental health solutions, Purdue University launched the Steps to Leaps initiative in 2019 to promote student well-being. It provided the tools and resources to build students' resilience skills and establish lifelong habits to help them realize their personal definitions of success. Working collaboratively with students, faculty, and front- line staff, the initiative identified five pillars, to address these concerns: well-being, leadership/professional development, impact, networks and grit. This article briefly outlined the program implementation and provides relevant theoretical frameworks in a case study format. It then summarized twelve key lessons learned from the two years of practice and concluded with a community perspective.
\end{abstract}

Keywords Student well-being $\cdot$ Mental health $\cdot$ Higher education $\cdot$ Intervention program $\cdot$ Resilience

With a growing demand for mental health services on campus and a recognition of the importance of college student well-being, higher education institutions are beginning to have a heightened interest in promoting well-being. In this article, we describe the Purdue Steps to Leaps initiative, which sets forth guiding principles and activities to bolster well-being within the Purdue student community. This case study illustrates the processes and stakeholders involved in developing and maintaining a well-being program in a university setting. These descriptions are generalized as actionable lessons that other institutions can glean from and apply.

Beth McCuskey

bmccuske@purdue.edu

1 Office of the Provost, Purdue University, 475 W Stadium Ave, West Lafayette, IN 47907, USA

2 Department of Psychological Sciences, Purdue University, West Lafayette, IN 47907, USA 


\section{Steps to Leaps}

Purdue University, located in the state of Indiana in the United States, enrolls nearly 46,000 students at the undergraduate and graduate level. As Indiana's land grant university, Purdue has historically maintained strength in its engineering and agriculture colleges while fostering a breadth of competitive degree programs across its ten academic colleges. In 2019, Purdue University launched Steps to Leaps, named to connect with the symbolism of the famous quote by alumnus Neil Armstrong. Steps to Leaps is a community-wide approach to improving the well-being of students broadly and is designed to foster growth in the areas of well-being, leadership, impact-making, networks, and grit.

The initiative has its origins as a strategy to respond to increasing demands for mental health services on campus and was developed in conjunction with investments made directly into mental health operations. The development of Steps to Leaps was organic and involved multiple iterations of discussion, a dive into research, and a true desire to understand the needs of students and to design a model that served them. Reflecting back on this approach, we can identify lessons that may be applied to other institutions considering efforts to build well-being more deeply into their culture. This paper discusses Purdue's approach to identifying the problem, the development of the initiative, and the preliminary outcomes of the model viewed through a community lens. It will also provide a retrospect of lessons learned along the way to provide considerations other institutions can use when exploring a system-wide approach to well-being.

\section{Lesson 1: Conduct environmental scans locally and broadly}

Steps to Leaps evolved from the need to address a rapidly increasing demand for campus mental health services. This phenomenon aligned with similar documented increases in the college-age population as a whole (Center for Collegiate Mental Health, 2018, 2020). The Center or Collegiate Mental Health gathers data from among its 600 member institutions. With a global footprint, the center's membership is comprised of primarily U.S. based institutions (Center for Collegiate Mental Health, 2020) and serves as a clearinghouse for institutional trends related to campus counseling centers. Among its findings, in 2015, the center reported a six-year counseling center utilization increase of 30-40\%; and identified the largest presenting mental health concerns to be depression and anxiety (Center for Collegiate Mental Health, 2020).

Purdue was also experiencing similar demand increases, including a $91 \%$ twoyear increase in students desiring to be seen immediately between 2016 and 2018. Other barometers at Purdue suggested similar findings, including concerns expressed by the academic colleges and student government and increases in reporting concerns to the Office of the Dean of Students.

While significant investments had been made to bolster staffing in preceding years, the growing demand for services combined with these expressed concerns drove the need to reimagine solutions. 
This environmental scanning process internally and externally served several purposes. First, the internal approach considered not only operating statistics from the counseling center, but student perceptions that they were not able to be accommodated. This information came through various channels, including conversations with students, concerns expressed by faculty and staff on campus who had heard of the challenges, and actual complaints received by administrators. This internal view combined data with perceptions and solidified the premise that there was a problem. Second, the external environmental scan also validated that these issues were being reported across the higher education sector and were not simply a problem on Purdue's campus. This helped set the tone that there were larger issues at stake than merely an operational problem. Finally, this approach grounded the problem in data and experiences both on campus and across the broader society, making it far more compelling to solve as a community concern.

\section{Lesson 2: Be aware of shifting demographics and perspectives}

Beyond the demand for mental health services, a secondary and related consideration also influenced the decision to build Steps to Leaps. In the summer and fall of 2018, Purdue's Office of Student Life conducted listening sessions with staff who worked directly with students. These sessions brought to light the perspective that student attitudes and behaviors were shifting.

Comments suggested that students were somehow different from those who attended just a few years ago. This perspective was repeated in every session and across multiple departments, suggesting the possibility of a generational shift.

Generational research is grounded in the perspective that "an individual's age is one of the most common predictors of differences in attitudes and behaviors" (Pew Research Center, 2015). This understanding can be a useful tool to tailor materials or communication strategies from a marketing or service delivery perspective. In 1991, Strauss and Howe posited that generations in the U.S. tend to cycle in four cohorts of approximately 20 years per group (W.

Strauss \& Howe, 1991). They traced these generational cohorts back to 1584 . They identified a pattern where a new generation tends to have similar characteristics as the generation most recently departing, giving some degree of predictability to the future.

Seemiller and Grace (2016) explored Generation Z, the current cohort in college. Among their findings, the authors suggest that it is important for these students to make a contribution - not for public recognition but for positive change. The authors also acknowledge several stressors pervasive with this generation, including the cost of college, finding a good job, and overall concerns for safety.

There are critics of generational theory and work places can provide intergenerational cohorts to study. Lester, et al. (2012), found a greater perception of differences across generational cohorts than actual differences in a midwestern (U.S.) organization. Costanza and Finkelstein (2015) posit that generations are actually three separate factors- the age of the individual, the period in which they live, and their cohort-or who they share experiences with. The authors caution organizations 
to avoid stereotyping individuals based on perceived membership in a generational cohort. It is wise to acknowledge compelling counter-perspectives and to factor this into program decisions.

At Purdue, there were multiple examples of student attitude or behavioral shifting that were presented in listening sessions with colleagues. First, this group noted the importance of mental health to this cohort. Students frequently discussed their own mental health needs, and staff also noted their own observations of concerning student behaviors. Second, in a division that traditionally hired upwards of 4,000 student employees to assist in areas such as recreation center management and dining operations, managers reported a decline in student interest in these roles. Students reported that if they were going to work, they wanted a direct connection between their job and their eventual career - a traditional "summer job" was no longer desirable. Third, both student employment managers and advisors of clubs and organizations reported that their students were not as dedicated to their roles and would frequently leave without warning. This was particularly noticeable during mid- terms and other times where academic demands were significant. When talking with students about this perception, they reported almost a laser-like focus toward academic achievement with other pursuits perceived as expendable. When digging deeper in these conversations, students expressed enormous pressure that they were putting on themselves to ensure that they would be successful in college and beyond.

Understanding generational differences, or shifts in perspective across age cohorts, helped set the tone for the community to explore new approaches to meeting students' needs. By framing the new student behaviors identified by faculty and staff as a generational paradigm shift, the Steps to Leaps team learned more about Generation $\mathrm{Z}$ and critically examined prior approaches to serving students to ensure that they still met today's student needs. As other institutions explore well-being strategies, it is important to understand their own population dynamics and how attitudes and behaviors shift over time.

\section{Lesson 3: Engage with stakeholders to build a solution}

After scanning the environment and discussing the evolution of student needs, the Steps to Leaps team began a process to develop the model. One of the most critical aspects of this part of the process was stakeholders' involvement - particularly students themselves - in the solution. The initiative was refined through multiple presentations, discussions, and listening sessions with faculty, staff and students. These included conversations in advisory committees, student government meetings, and open fora. Multiple presentations about Generation $\mathrm{Z}$ were conducted to create opportunities to understand that millennials were no longer the dominant generation on campus. This mindset shift helped to generate even more dialogue and ideas.

Finally, a workshop was held with an invited group of about 30 faculty, staff, and students. Using a design thinking model, the workshop focused on the end users' experiences and helped to further coalesce around five pillars that would become the core of the model, also identifying "Steps to Leaps" as the initiative's name. 
Steps to Leaps would not have evolved without the engagement of stakeholders. Their engagement helped set the stage for a broader initiative tied to overall wellbeing rather than simply addressing mental health resources or tweaking programs to appeal to a new generation of students. Student feedback helped us to identify issues that were on their minds and also to create pillars with themes that resonated.

\section{Lesson 4: Create a broad approach to well-being: The Steps to Leaps pillars}

Steps to Leaps was never thought of as a program per se but as a thematic approach to develop skills and foster resilience for lifelong benefit for the participants. While initially designed for students, the initiative transcends age groups. It is important to note that the Steps to Leaps pillars were never intended to be a mutually exclusive set of factors but instead were selected and refined because they resonated with the ideas and concerns generated during the listening sessions. These pillars are also rooted in scientific research around key constructs within social sciences, and this research has guided their development and will allow us to continue to test and refine the model.

Well-being Staying healthy in body, brain and spirit is a life-long journey. Learn strategies to improve your own well-being with steps to security, health and prosperity.

The well-being pillar encompasses aspects related to health in its broadest sense, borrowing the definition of "a state of complete physical, mental and social wellbeing and not merely the absence of disease or infirmity" (World Health Organization, 2005b). Practitioners and researchers view well-being as a multidimensional construct that spans physical, emotional, spiritual, psychological, and economic aspects (e.g., Csikszentmihalyi, 2009; Kobau et al., 2010; World Health Organization, 2005a). Higher levels of well-being are related to a variety of benefits, including marriage, longevity, higher income, and better job performance (Diener \& Chan, 2011; Judge et al., 2001; Lyubomirsky et al., 2005). Well-being is malleable, and individuals and communities can engage in active practices for its promotion (Breslow, 2006; Dahl et al., 2020; Tay \& Kuykendall, 2013). Higher education as a whole has been linked to higher degrees of well-being throughout life. A metaanalysis published in 2016 explores the impact of higher education on happiness, health, transmission of benefits to children, and community involvement and notes, "Across these diverse outcomes, evidence clearly finds that college graduates have an enriched quality of life compared to their less educated peers" (Mayhew et al., 2016). Purdue's efforts are striving to help students thrive over time and across various life domains through multiple channels.

For example, Purdue developed a holistic approach to mental health services, including refocusing efforts in the Office of the Dean of Students (ODOS), a department that helps students navigate the complexities of college life, and making process changes to the Counseling and Psychological Services (CAPS) department. Given that many students expressed concerns about their financial health, Purdue also added Boiler Financial Track, a program designed to help students refine 
financial literacy skills. Created with a Purdue Federal Credit Union grant, the program offers group presentations and one-to-one education.

Other than providing resources to help students flourish, the well-being pillar recognized the importance of mental health awareness to create a safe environment and to involve those who needed the help the most. Research pointed out the widespread misunderstanding and prejudice against people with mental disorders, which to a large extent prevents them from seeking necessary resources (Emmet, 1998; Frese, 1998; Morselli, 2000). To combat this situation, the World Health Organization published a series of documents that outlined the importance of advocacy efforts, and specific actions organizations can do to help educate the public (World Health Organization, 2003).

To endorse the call for raising mental health awareness, Purdue Student Government (PSG) and Graduate Student Government (PGSG) developed an awareness campaign to destigmatize mental health. ODOS launched a train-the-trainer program that brought the Mental.

Health First Aid program to campus, and CAPS developed an infographic to demonstrate the wide range of support options for students as part of their larger communication strategy to launch their new service model. Further, a faculty member in Industrial-Organizational Psychology was appointed to help coordinate the Steps to Leaps effort across interested faculty to bring in insights from different disciplines. He also launched a student course on well-being to help students understand the theoretical underpinnings of the construct.

Leadership and Professional Development Boilermakers have a strong tradition of leadership in their careers and communities. Learn how to tap into your own strengths as you become the next generation of leaders with steps to initiative, guidance and direction.

While our society demands leaders who can effectively handle complex situations and provide creative solutions, there has been a decreasing trend in public's confidence in leaders in sectors such as press, executive branch, and nonprofit organizations (Montoya et al., 2007). As a response, the Steps to Leaps incorporated its second pillar, aiming to build students' leadership skills and provide them with guidance to fulfill their professional aspirations. Empirical research has found that participation in leadership activities provides invaluable opportunities for students to develop civic responsibility, multicultural awareness and personal and societal values (Cress et al., 2001). These qualities resonate with some of the critical components of modern theories of leadership (e.g., Allen et al., 1998).

Purdue historically has had a strong tradition in developing leaders and, through the generosity of an alumnus, launched the Leadership and Professional Development Initiative. The Roger C. Stewart Leadership Experience at Purdue (LEAP) program engages new students with the Gallup strengths model (Gallup, 2017) to build their leadership capacity. A variety of program offerings broaden this experience as students progress through their college years.

As Steps to Leaps developed, it was clear that this strengths-based model of leadership was a natural fit with the overarching goals of the initiative. First, Gallup's approach suggests that individuals function at their best when tapping into 
their strengths rather than focusing their energies on trying to cure a deficit (Gallup, 2017). This naturally ties to well-being themes.

Taking that a step further, to accomplish big goals, one must function at their best, tying the strengths-based approach to the impact pillar.

It was natural to align the Leadership and Professional Development Initiative to the Steps to Leaps framework, further promoting the concept that the framework was a theme or a set of organizing principles rather than a brand-new set of programs.

Impact Every Boilermaker strives to leave their footprint, and world-changing examples can be found throughout Purdue's rich history. Learn the importance of creating an impact through your everyday actions with steps to modify, touch and influence.

The impact pillar closely aligns to a sense of meaning in life that usually comes from personal achievement and a positive influence on society (McDonald et al., 2012; McKnight \& Kashdan, 2009). It is arguably the most nebulous of the five and ties directly to the themes expressed by students and in the literature associated with Generation Z (Seemiller \& Grace, 2016). Students want to make a big difference in the world and, in some cases, already are, evidenced by Greta Thunberg's efforts to draw attention to climate change and selection as Time's Person of the Year for 2019 (Alter et al., 2020). The impact pillar encourages students to pursue something larger than their original selves and supports these big dreams with a focus on the small steps in their daily lives, just as the program name Steps to Leaps suggests.

Research has shown that having a purpose is beneficial in many aspects of life.

Academically, students with a self-transcendent purpose in learning (e.g., "I want to gain skills that I can use in a job that help others"), compared to those with a self-oriented purpose (e.g., "I want to learn more about my interests"), resulted in better grades, higher academic self- regulation and increased persistence in learning (Yeager et al., 2014). Linking to well-being, purposeful and prosocial individuals reported positive life outcomes, including higher life satisfaction (Steger \& Kashdan, 2013), lower depression (Disabato et al., 2017), and lower mortality rate (Brown et al., 2003; Oman et al., 1999).

At Purdue, there are many opportunities for students to foster a sense of meaning and actively make an impact, such as participating in service organizations and fundraising. Civic Engagement and Leadership Development, a unit of the LPDI, is designed for students to engage in their communities. Students can also develop their entrepreneurial skills through an academic certificate in entrepreneurship and innovation or participate in a host of other programs and activities through the Burton D. Morgan Center for Entrepreneurship.

A student's developmental journey includes identifying how they will tap into their talents and interests as they build their lives within and beyond college. The impact pillar supports this development.

Networks A strong network serves as a resource throughout your life. The tightest networks are created by connections with individuals and require active participation. Learn how to build your network with steps to making connections and bonds. 
The networks pillar emphasizes initiating and maintaining positive relationships throughout one's life. Going beyond networking, networks offer essential resources for emotional, informational, and instrumental support (Cohen, 2004). Research has found that students with stronger social connections are better at coping through hard times (Dumont \& Provost 1999; Lakey \& Cohen, 2000) and experience fewer mental health problems (Hefner \& Eisenberg, 2009). Literature in higher education also suggested that social interconnections are an important part of college student retention (Tinto, 1993). These findings guided the development of the networks pillar, aiming to equip students with multiple communication skills and networking opportunities, from increasing the number of network contacts to strengthening their existing social ties.

To achieve these goals, Purdue creates opportunities for student involvement. This can take place by participation in nearly 1,000 student clubs and organizations, through important connections made with faculty members, and by engaging in student employment on campus. Additionally, robust learning programs are administered in residence halls, creating opportunities for students to enlarge their networks.

Grit Life is full of ups and downs. Learn strategies to tap into your inner fortitude to overcome challenges and become your best Boilermaker with steps to resolve and character.

Grit, as framed at Purdue, ties to resiliency skills. There are two important concepts in its design. First, we follow the theoretical underpinnings of Carol Dweck's growth mindset, which suggests that mindful mental tweaks can help individuals frame challenges from fixed and insurmountable hurdles to growth and development opportunities (Dweck, 2006). Purdue employs the growth mindset theory before matriculation. In collaboration with PERTS.net, all incoming students are invited to participate in a well-established intervention program to help them apply growth mindset thinking to a problem (Paunesku et al., 2015; Yeager et al., 2016).

Pre- and post-assessments are also conducted to assess whether the activity facilitated learning.

Moreover, Angela Duckworth's research is also fundamental to the grit pillar. Her research suggests that beyond talent and intelligence, grit, an outcome of both passion and perseverance, also contributed to individual achievement (Duckworth et al., 2007). Recent research also laid out the possibility for community efforts to help students cultivate grit across time (Verdín et al., 2018). Critics of this approach have suggested that these variables in totality are not predictive of success, but that perseverance does play a role (Credé et al., 2017). Despite the critiques of grit as a construct, the word itself resonated with Purdue students. Because of grit's connotation with hard work and effort, students found it the best name for the pillar.

One of the strategies Purdue has used to discuss the grit pillar has been student stories. Many students have shared that they believe that they alone have setbacks while their peers are doing fine. Student volunteers share their own stories within peer groups or through video recollection of their experiences. Students report that they find these recollections helpful as they set their expectations for success during college. 


\section{Integrating Diversity, Equity, and Inclusion}

The five pillars were developed through an iterative process with faculty staff and students. During the formation of the model, we explored how best to ensure that Steps to Leaps reflected the values of diversity, equity, and inclusion (DEI). Given that DEI is integral to all the individual pillars, we discussed whether to embed DEI within the individual pillars or to create a separate pillar focused on DEI, knowing that the area was also identified as a leadership competency in the Leadership Pillar. In the end, the team believed that DEI was better served by integrating it throughout the pillars rather than building it as a separate one. The steering committee-a diverse group in their own right- reviewed this decision again in 2021. Even after considering the intercultural struggles of the last two years, the team believes the model is stronger, with inclusion as foundational and integrated across all the pillars rather than standing alone. We are moving forward with a commitment to DEI and will continue to assess whether Steps to Leaps is hitting this mark.

\section{How the Pillars Intertwine}

The Steps to Leaps pillars were developed to appeal to students' needs and faculty and staff who work with them. They were not designed to be independent variables. One approach to conceptualize the pillars is to consider how they can connect.

If well-being is the ultimate goal of Steps to Leaps, the Leadership and Impact pillars are action orientations that students can take toward the goal. Leadership refers to the inward-facing continuous growth and skill development, while Impact is the outward-facing deployment of those skills. The Grit and Networks pillars support these activities through the inward mindset of Grit and outward connections of Networks.

Purdue developed the Steps to Leaps pillars through a messy, iterative process with many stakeholders. This stakeholder involvement helped to create institutional buy-in for the model.

While the pillars themselves are broad enough to apply beyond Purdue, gaining stakeholder engagement in need for a well-being strategy and discussing the pillars unique applications to their institutional setting are lessons that can translate to new locations.

\section{Lesson 5: Develop a Deployment Plan}

Steps to Leaps began as an effort to ensure programs and services were meeting today's student needs. It was not perceived as an initiative or program but rather a way to evolve existing work. While the initial focus was to address the burgeoning demand for mental health services and ensure that departments were responsive to the generational shift underway, the strategy evolved to build comprehensive 
institutional support for well-being. Purdue sought to develop programmatic themes and associated language for existing areas to tie into, with the intention for programs to evolve to the new model naturally. This broad focus required a new strategy.

As the Steps to Leaps pillars were developed, faculty and staff engaged in the process began to ideate how they could incorporate the pillars in their respective work with students. This resulted in a large number of ideas without a clear approach to define how they would be implemented or how they were interconnected. To help manage this process, we developed four targeted approaches to launching Steps to Leaps on campus: Research, Communication, Content Development, and Coaching/Support. In our model (illustrated in Fig. 1), each of these approaches is linked to either a key theme we are focusing on, or an existing campus structure that plays a role in deployment.

Leaders were selected to work with each of these main areas to promote and assess the model. Additionally, we recognized the importance of technology in the program rollout. As indicated in the diagram, technology spans each of the deployment approaches. By developing a deployment plan, the team was able to align similar work efforts and created accountability through the leadership model. A Steps to Leaps steering committee consists of the leads for each of the deployment approaches and others linked to the effort's success. This group meets monthly to review progress and the diagram of our deployment strategy serves as a visual reminder as we align efforts with the appropriate team.

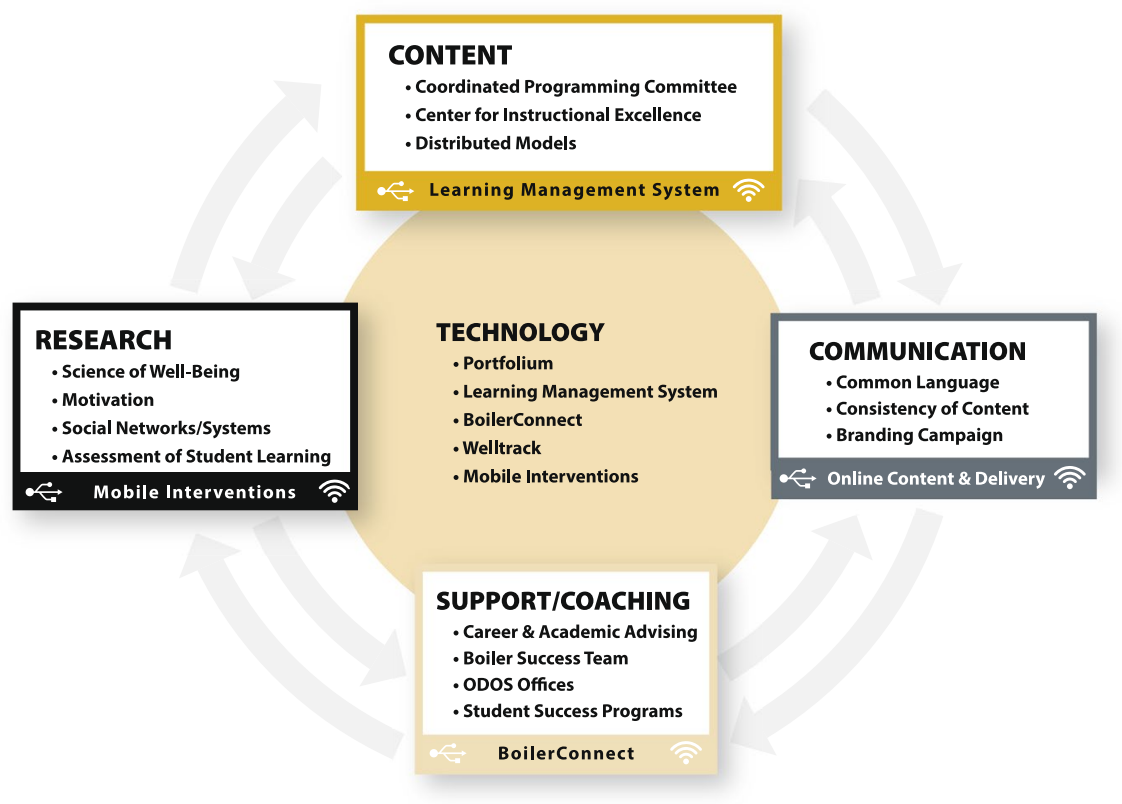

Fig.1 Deployment structure of Steps to Leaps 


\section{Lesson 6: Ground well-being efforts to salient research}

The research team seeks to identify faculty conducting research related to the Steps to Leaps pillars, providing collaboration for them to discuss findings and find mutual areas of growth. This team is also charged with assessing the impact of Steps to Leaps. Initial efforts include convening the research collaborative, collecting information about existing assessment efforts on campus, and developing and piloting an assessment effort specific to the Steps to Leaps pillars.

Besides the obvious benefits of grounding an initiative in relevant research particularly at a higher education institution - embedding a research arm in the deployment model served two additional purposes. First, it provided a research community for faculty interested in this work. At a large research-based university, there may be limited opportunities for faculty to connect outside of their academic departments. Steps to Leaps provides an avenue to build networks beyond one's academic home. Second, the involvement of research faculty helped by adding a layer of academic legitimacy to the initiative. This helped pique further interest by academic colleagues and helped the initiative grow.

\section{Lesson 7: Communication is a critical component of launching a new initiative}

As we conceptualized the Steps to Leaps deployment across campus, it became obvious that communication was vitally important to the process. Elements embedded in the communication model include developing a brand, developing a common language, and creating a consistent content development approach. Communication also took into consideration how we kept constituents abreast about the initiative and its related programs and projects.

Brand development included naming and creating a logo for the effort, both tied to alumnus Neil Armstrong and the 1969 lunar landing. The concept of "giant leaps" also had significant traction as part of the branding campaign for Purdue's sesquicentennial celebration, further solidifying the language. Another strategy that continues to be difficult to implement is to develop a common language to discuss programs that are linked to well-being. As a sizeable decentralized university, many existing efforts can tie in. However, many of these have longstanding language or acronyms. While we never asked people to go to the extent of changing their program names, we hoped to build linkages between their efforts and Steps to Leaps. This requires a balanced approach as we do not coopt others' efforts, but merely highlight the breadth of offerings across campus. We have made inroads, but sometimes this has been difficult as these programs have existing identities.

\section{Lesson 8: Develop content to link with existing operations}

Steps to Leaps were not developed as a program but instead sought to link existing efforts under a well-being umbrella, filling in gaps with new material. This 
approach allowed new resources to be used to promote existing activities while selectively creating new ones cohesively. This helped to minimize budgetary impact and also amplified good work that was already taking place.

Partnerships across departments were also crucial in the deployment of Steps to Leaps. For example, Purdue's Center for Instructional Excellence (CIE) focuses on teaching and has been an integral part of the initiative. A partnership between CIE and the Department of.

Chemistry helped foster a new curriculum for graduate teaching assistants linked to the Steps to Leaps pillars. This helps present the material to undergraduate students but also emphasizes the pillars to graduate students as part of their professional development as teachers.

To quickly build new Steps to Leaps content, templates were developed to serve as an aid. This was particularly useful as we began the process as undergraduate interns were responsible for developing much of the initial program content. As the program has evolved, we have tended to relax in using the templates as we did not want that to be a barrier to new ideas and growth. Early content successes include learning modules, video content, a newsletter and tip sheets, periodic dialogue sessions, and publication of a well-being tip of the week.

\section{Lesson 9: Align student support initiatives under the well-being umbrella}

Supporting students in classroom learning as well as in personal growth is a critical element of Steps to Leaps. As Steps to Leaps evolved, it became important to work closely with departments charged with student support and emphasize their well-being efforts as part of a holistic approach. For example, to accommodate the increasing demand for mental health services, the Counseling and Psychological Services (CAPS) care model was adapted to focus on rapid response. This service change was promoted in conjunction with other support efforts on campus to give students a menu of offerings depending on their needs.

This approach was designed to foster a culture of well-being on campus. While individual programs may provide high service levels and student satisfaction, it is difficult for any one of them to independently drive the culture at large. By aligning efforts and cross-promoting programs, we can discuss the breadth of efforts and demonstrate how they inter-connect. This helps to set the tone for community well-being overall.

Besides the revamping of CAPS, other efforts include broad educational strategies to build awareness of mental health, aligning wellness activities such as exercise, nutrition, and financial well-being under the Steps to Leaps umbrella, and partnering with the undergraduate and graduate student governments of Purdue (PSG and PGSG) and Human Resources to promote mental health awareness. Additionally, Purdue's Leadership and Professional Development (LPDI) department aligns its skill development efforts under the Leadership pillar, linking signature programs such as Gallup Strengths to well-being. 


\section{Lesson 10: Identify relevant technological resources to support the program}

Launching Steps to Leaps required us to look at technological solutions for each of the deployment methods. Research efforts required assessment tools, while content delivery required a secure web-based approach to ensure modules were accessible only to university-related individuals. Communication required a multi-layered approach, tying in through social media, a web-presence, and the development of written and video materials. Student support efforts needed a mechanism to link the variety of efforts taking place while recognizing legal and privacy requirements. In addition, support efforts are being deployed via technology. A mobile app solution was even piloted as an approach to build virtual networks and support structures.

With the exception of the mobile app, Purdue was able to use existing technology to launch the program.

\section{Lesson 11: Launch big}

Purdue launched Steps to Leaps formally in September 2019 with a daylong summit featuring Purdue's researchers and discussions about applying the pillars to the work of the University. A panel of Purdue students also discussed their own experiences, the intuitive nature of the pillars, and how they could use the pillars to develop their skillsets moving forward.

The program featured remarks from Purdue's provost, emphasizing the importance of the initiative. Participants were invited to weigh in on the pillars and how they might incorporate the content into their existing work. The session wrapped up by inviting participants to participate in a series of workshops developed to learn from each other's efforts.

A similar program was held for student leaders on campus. Student organizations were invited to participate in the student-led dialogue about Steps to Leaps and how they could incorporate the materials into their own leadership structures.

\section{Lesson 12: Be prepared to adapt: COVID-19 disrupts deployment}

In March 2020, as COVID-19 began spreading in the U.S., Purdue, like many institutions, transitioned to remote delivery of courses for the remaining semester. Estimates suggested $25-33 \%$ of students remained in the greater community, but most departed for home. While the campus did not completely shut down, most activities went online, other than clinical and laboratory experiential education.

The campus-wide rollout of Steps to Leaps was beginning to take root when the online transition occurred. Team members also flipped Steps to Leaps content online, with virtual educational sessions (Discussion and Dialogue) for faculty and staff and well-being nudges sent to students via social media. Responding to this pandemic at its core required a focus on well-being and resiliency.

While many of the initial plans for Steps to Leaps were put on hold to respond to the pandemic, several themes emerged. First, the virtual content for faculty and staff 
had robust attendance, even more than face-to-face meetings where a free lunch was served. Second, the pandemic drove emphasis on well-being topics. Steps to Leaps content was still being accessed. Third, students who were spending their classroom time online were less interested in doing.

additional online workshops. The pivot to nudges and reminders through social media emerged as a response. Finally, students who gained from the model wanted to share their talents and are interested in creating a student organization or club dedicated to the Steps to Leaps pillars.

The launch of a university-wide initiative can be complex and messy. We have identified these 12 lessons as the key to our ability to launch and maintain Steps to Leaps as a community well-being initiative. Table 1 illustrates how Purdue applied the lesson to its own culture and suggests considerations for other communities who are considering replicating a similar initiative.

\section{Designing and Implementing a Well-Being Initiative in a University Setting}

Community has a powerful influence on its members. In secondary schools, the racial climate was found to predict discrimination and perception of fairness (Mattison \& Aber, 2007), and political climate was related to belongingness and sense of membership (Vieno et al., 2005). In higher education, students who perceive their institution provides a supportive environment are more successful in a myriad of educational outcomes (Mayhew et al., 2016). Moreover, researchers and practitioners rely on community-based intervention programs to promote student well-being in various aspects (e.g., LaCosse et al., 2020; Okonofua et al., 2016; Yeager et al., 2016). Purdue University strives to make a better community for students to thrive together. Steps to Leaps is a natural evolution of this goal and was developed and deployed with multiple stakeholder groups. This campus-wide well-being effort was grounded in a community approach from its ideation to deployment.

\section{A Community Approach}

Steps to Leaps' inception was grounded in a community-wide assessment of student needs and progresses beyond a single department or program. Following the literature on community development (e.g., Lee et al., 2015), the overarching goal is to strengthen community well-being by encouraging the Purdue community's direct participation. Steps to Leaps uses measures of individual well-being and community well-being to help inform the direction of the program. To gather information on student needs, a series of conversations were held with various stakeholder groups, including students, faculty, and staff. These conversations helped us to develop frameworks of community indicators to help structure program delivery, identify student concerns, and validate relevant concepts.

As we progressed beyond merely looking at the counseling center's ability to meet student needs, we identified a myriad of issues and concerns that could be 


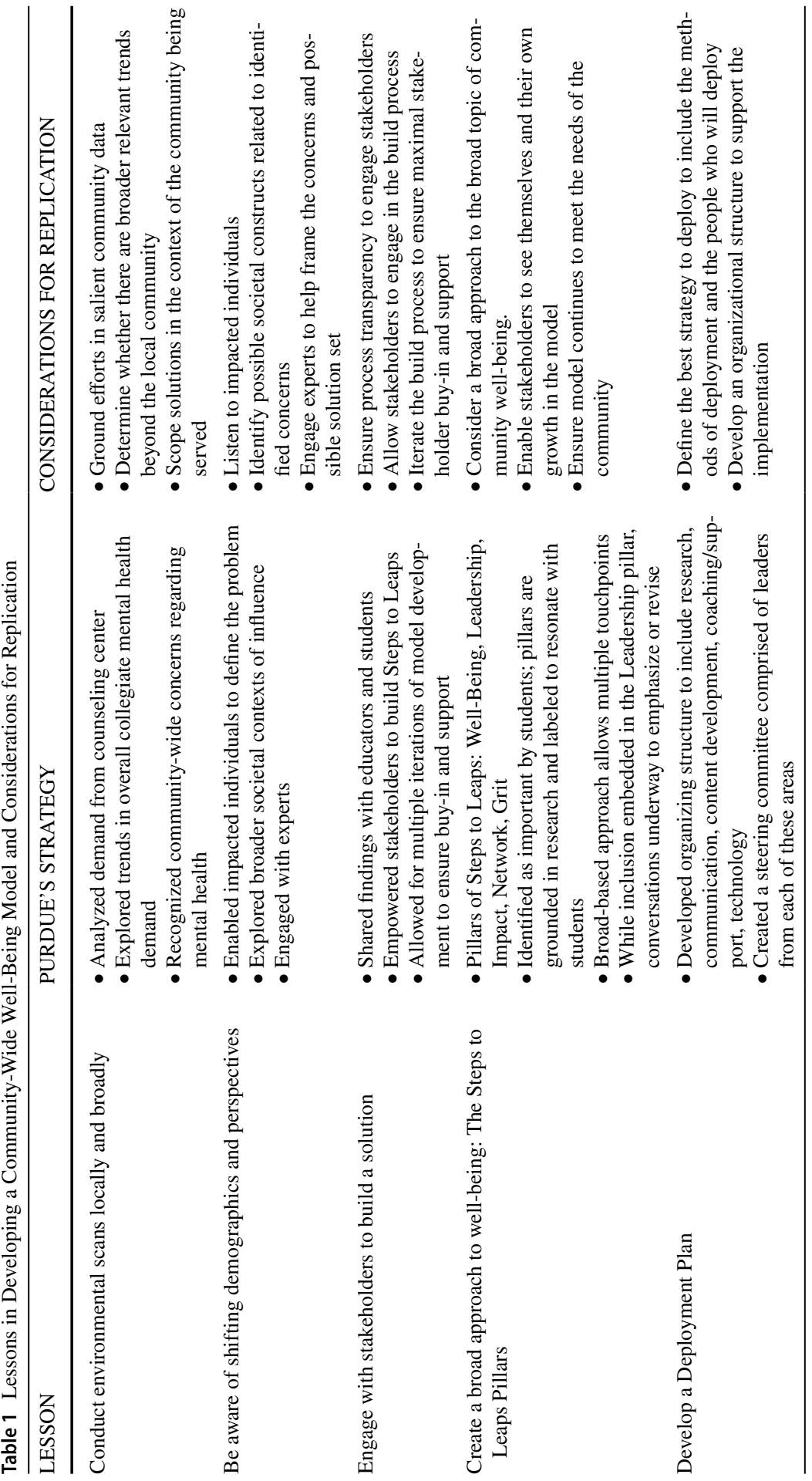




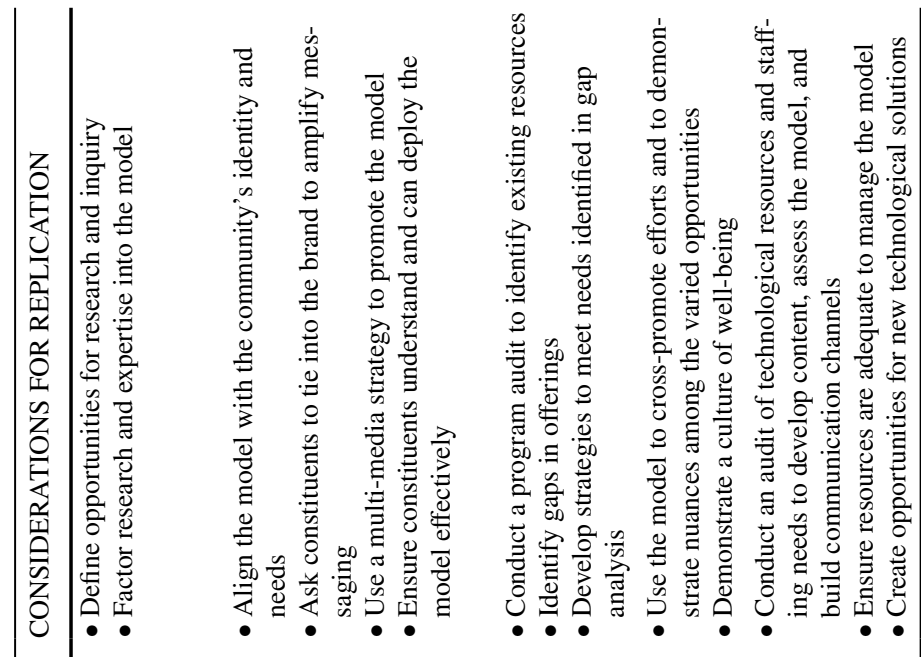

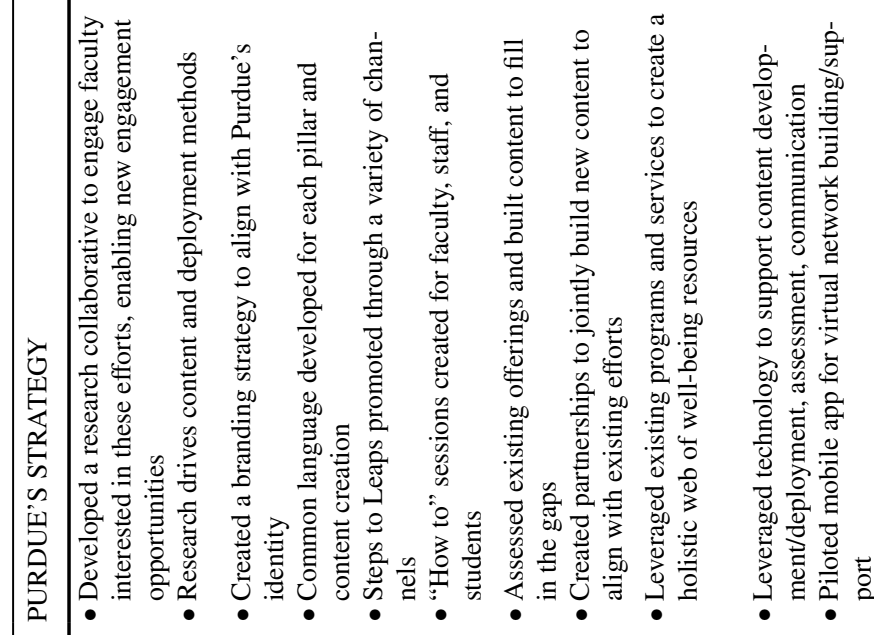

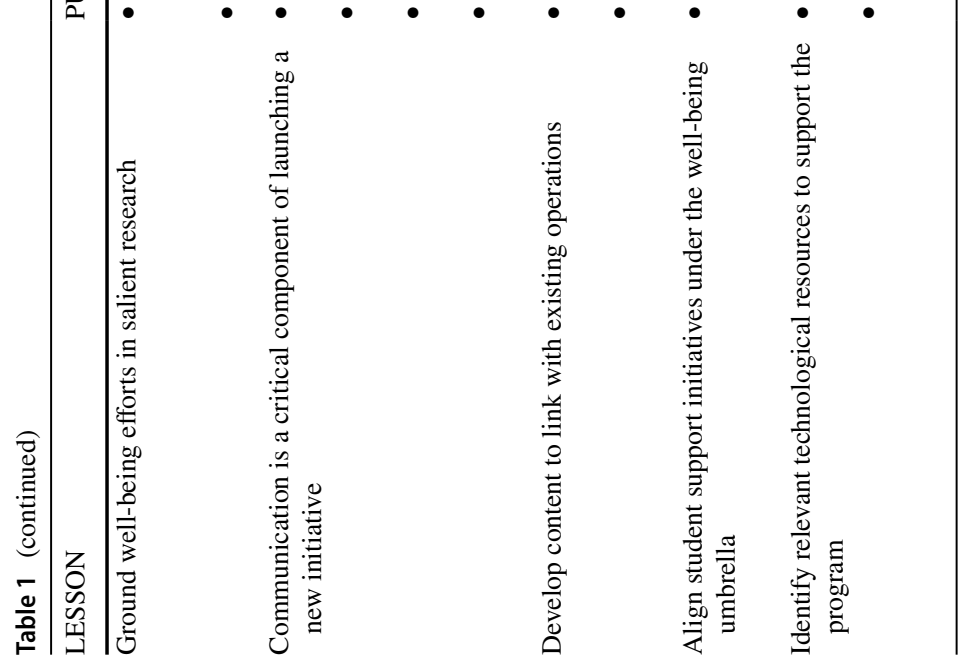




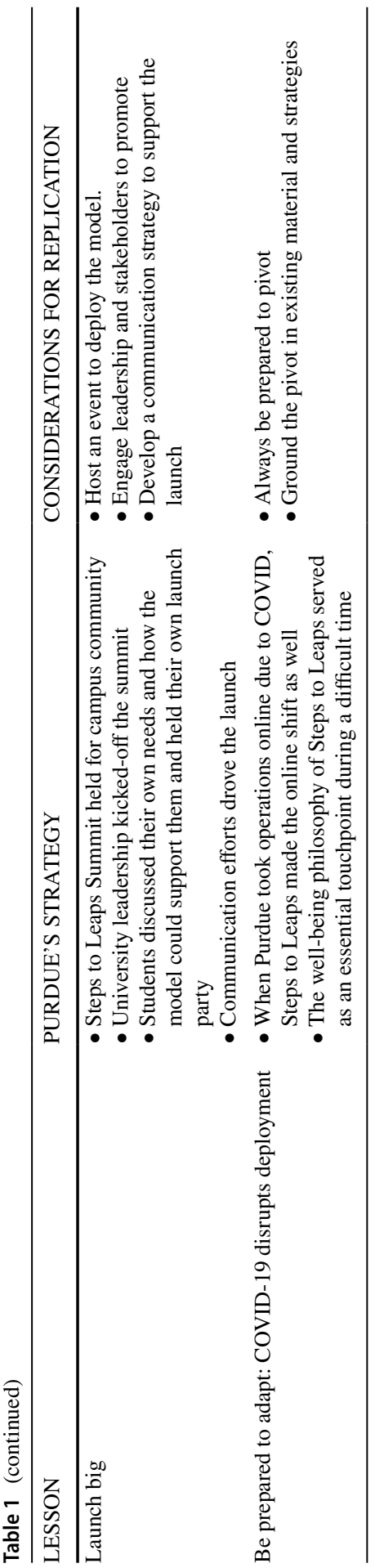


framed as community indicators. These included stressors such as difficulty making friends, financial concerns, or academic pressures. It was possible to help many of these students outside of the clinical sphere through both one-to-one discussion and through community-wide interventions. This combination of individual and community strategies allowed us to identify places where support was already being provided or where we had gaps in how we were serving our students.

Steps to Leaps planners have also made use of institutional data such as demographics, data from institutional surveys, and information gleaned from participating in multi-institution surveys. While not assessments of Steps to Leaps or the pillars per se, the ability to ground the program planning in existing information helped us to understand the baseline and to develop plans for assessment where data is lacking.

A premise embedded within the community approach was the importance of including students in both the initiative's design and deployment. We wish to learn from the students' own observations of how well Purdue is helping them flourish in multiple domains. Other than personal well-being, the initiative also touches on societal well-being, or "the perception of people's common or shared experience of life," which serves as a more realistic and actionable indicator on the community level (Cummins et al., 2003; Eckersley, 2000). This focus was embedded in a design thinking workshop held as part of the planning efforts and is evidenced through student interns who develop and present content for fellow students.

Students identified many recurring themes tied to well-being, such as managing stressors, fear of failure, mindfulness, and overall physical, emotional, and spiritual health. Including students in the planning efforts helped define the problem, find and highlight existing solutions, and create new content where necessary. The approach of linking existing resources and completing gaps not only minimized the resources necessary to launch the initiative, but it also highlighted many existing initiatives in new ways. Highlighting existing community strengths rather than layering new initiatives upon them further strengthens the community through validating its members' efforts.

Another element of the community focus is the inclusion of alumni in the model. While faculty, staff, and students are the primary participants, alumni have provided their insights for the design of the project and serve in mentorship roles to students. This intergenerational perspective helps students recognize the lifelong benefit of the Steps to Leaps pillars and relate to stories shared by alumni.

Finally, an interesting offshoot of this community approach is a research collaborative developed to link faculty who have a research interest in an element of Steps to Leaps. This effort is a multi-disciplinary approach that links faculty members who see their work aligning with the pillars and can connect their research to college students.

The biggest challenge with the community-based approach is the complexity of managing it. In a large complex organization, multiple stakeholder groups can have competing priorities and resources. In addition, Steps to Leaps sought to tap into existing programs by using communication as a vehicle to highlight them under the Steps to Leaps umbrella. While generally successful, it was sometimes difficult convincing people to link their efforts to the initiative. The University's senior leadership supported Steps to Leaps, signifying that it was important to align efforts. This helped immeasurably.

Creating a deployment model and graphic, then using the model to charge a steering committee also helped to manage this broad initiative. Leaders tasked with individual 
aspects of the project were better able to focus their efforts yet see the bigger picture in steering committee meetings. Another element that helped build community collaboration was facilitation work.

Multiple work sessions were held to gather a variety of opinions that were included in the initiative. These efforts do take time, and there were frequently competing perspectives that had to be navigated.

The community approach can also make assessment efforts more complex. It is relatively easy to measure the demand for campus mental health services. However, assessing the impact of Steps to Leaps pillars on the individual as well as on the community requires a relatively comprehensive perspective. Community well-being is often conceptualized on a collective level that encompasses more than the sum of individual well-being (Lee \& Kim, 2015). In its measurement, recent research on social indicators and quality of life emphasized the equal importance of subjective (personal well-being and perceived cultural values of the community) and objective (material and social circumstances at the collective level) measures (Cummins, 1998; Sung \& Phillips, 2018). Correspondingly, we designed and administered pilot surveys that recorded variables including demographics, happiness and skills, belongingness to and trust in the community, and qualitative feedback of student experience.

Defining and assessing well-being across a large complex organization is a challenge, and while pilots have been conducted, population data has not yet been collected. Assessment as a whole will be the next evolution of the initiative.

Purdue prioritizes well-being as a practical skill that ties with its educational and developmental mission: skills can be built and grown. While understandably, mental health issues need to be clinically managed, Steps to Leaps provides opportunities to help students manage situations before they become overwhelming. We believe that the pillars embedded in Steps to Leaps can be nurtured in college and fostered throughout our students' lifetimes - with an ultimate goal of better quality of life.

Funding No funding was received to assist with the preparation of this manuscript.

Data Availability Not applicable.

Code availability Not applicable.

\section{Declarations}

Conflicts of Interest The authors acknowledge that there is no conflict of interest to be disclosed.

\section{References}

Allen, K. E., Stelzner, S. P., \& Wielkiewicz, R. M. (1998). The ecology of leadership: Adapting to the challenges of a changing world. Journal of Leadership Studies, 5(2), 62-62.

Alter, C., Haynes, S., \& Worland, J. (2020). Greta Thunberg is TIME's 2019 person of the year. Time. https://time.com/person-of-the-year-2019-greta-thunberg/. Accessed 9 Jan 2021.

Breslow, L. (2006). Health measurement in the third era of health. American Journal of Public Health, 96(1), 17-19. https://doi.org/10.2105/AJPH.2004.055970. 
Brown, S. L., Nesse, R. M., Vinokur, A. D., \& Smith, D. M. (2003). Providing social support may be more beneficial than receiving it: Results from a prospective study of mortality. Psychological Science, 14(4), 320-327. https://doi.org/10.1111/1467-9280.14461.

Costanza, D. P., \& Finkelstein, L. M. (2015). Generationally based differences in the workplace: Is there a there there? Industrial and Organizational Psychology, 8(3), 308-323. https://doi.org/10. 1017/iop.2015.15.

Center for Collegiate Mental Health. (2018). Center for Collegiate Mental Health (CCMH) 2017 Annual Report. Publication No. STA 18-166. In Center for Collegiate Mental Health. Center for Collegiate Mental Health. https://eric.ed.gov/?q=source\%3A\%22Center+for+Collegiate+Mental+Health\%22\&id=ED586224. Accessed 2 Mar 2021.

Center for Collegiate Mental Health. (2020). Center for Collegiate Mental Health (CCMH) 2019 Annual Report. Publication No. STA 20-244. In Center for Collegiate Mental Health. Center for Collegiate Mental Health. https://eric.ed.gov/?id=ED602859. Accessed 2 Mar 2021.

Cohen, S. (2004). Social relationships and health. The American Psychologist, 59, 676-684.

Credé, M., Tynan, M. C., \& Harms, P. D. (2017). Much ado about grit: A meta-analytic synthesis of the grit literature. Journal of Personality and Social Psychology, 113(3), 492-511. https://doi. org/10.1037/pspp0000102.

Cress, C. M., Astin, H. S., Zimmerman-Oster, K., \& Burkhardt, J. C. (2001). Developmental outcomes of college students' involvement in leadership activities. Journal of College Student Development, 42(1), 15-27. https://eric.ed.gov/?id=EJ624495. Accessed 2 Mar 2021

Csikszentmihalyi, M. (2009). Flow: The psychology of optimal experience. Harper Collins.

Cummins, R. A. (1998). The second approximation to an international standard for life satisfaction. Social Indicators Research, 43(3), 307-334. https://doi.org/10.1023/A:1006831107052.

Cummins, R. A., Eckersley, R., Pallant, J., van Vugt, J., \& Misajon, R. (2003). Developing a national index of subjective wellbeing: The Australian unity wellbeing index. Social Indicators Research, 64(2), 159-190. https://doi.org/10.1023/A:1024704320683.

Dahl, C. J., Wilson-Mendenhall, C. D., \& Davidson, R. J. (2020). The plasticity of well-being: A training-based framework for the cultivation of human flourishing. Proceedings of the National Academy of Sciences, 117(51), 32197-32206. https://doi.org/10.1073/pnas.2014859117.

Diener, E., \& Chan, M. Y. (2011). Happy people live longer: Subjective well-being contributes to health and longevity. Applied Psychology: Health and Well-Being, 3(1), 1-43. https://doi.org/10. 1111/j.1758-0854.2010.01045.x.

Disabato, D. J., Kashdan, T. B., Short, J. L., \& Jarden, A. (2017). What predicts positive life events that influence the course of depression? A longitudinal examination of gratitude and meaning in life. Cognitive Therapy and Research, 41(3), 444-458. https://doi.org/10.1007/ s10608-016-9785-x.

Duckworth, A. L., Peterson, C., Matthews, M. D., \& Kelly, D. R. (2007). Grit: Perseverance and passion for long-term goals. Journal of Personality and Social Psychology, 92(6), 1087-1101. https://doi.org/10.1037/0022-3514.92.6.1087.

Dumont, M., \& Provost, M. A. (1999). Resilience in adolescents: Protective role of social support, coping strategies, self-esteem, and social activities on experience of stress and depression. Journal of Youth and Adolescence, 28(3), 343-363. https://doi.org/10.1023/A:1021637011732.

Dweck, C. S. (2006). Mindset: The new psychology of success. Random House Publishing Group.

Eckersley, R. (2000). The state and fate of nations: Implications of subjective measures of personal and social quality of life. Social Indicators Research, 52(1), 3-27. https://doi.org/10.1023/A: 1007071621613.

Emmet, W. (1998). A family advocate's reply: Why consumers and family advocates must work together. Psychiatric Services, 49(6), 764-765. https://doi.org/10.1176/ps.49.6.764.

Frese, F. J. (1998). Advocacy, recovery, and the challenges of consumerism for schizophrenia. The Psychiatric Clinics of North America, 21(1), 233-249. https://doi.org/10.1016/s0193-953x(05)70369-5.

Gallup. (2017). Clifton strengths for students: Your strengths journey begins here. Simon and Schuster.

Hefner, J., \& Eisenberg, D. (2009). Social support and mental health among college students. American Journal of Orthopsychiatry, 79(4), 491-499. https://doi.org/10.1037/a0016918.

Judge, T. A., Thoresen, C. J., Bono, J. E., \& Patton, G. K. (2001). The job satisfaction-job performance relationship: A qualitative and quantitative review. Psychological Bulletin, 127(3), 376-407. https:// doi.org/10.1037/0033-2909.127.3.376.

Kobau, R., Sniezek, J., Zack, M. M., Lucas, R. E., \& Burns, A. (2010). Well-being assessment: An evaluation of well-being scales for public health and population estimates of well-being among US 
adults. Applied Psychology: Health and Well-Being, 2(3), 272-297. https://doi.org/10.1111/j.17580854.2010.01035.x.

LaCosse, J., Canning, E. A., Bowman, N. A., Murphy, M. C., \& Logel, C. (2020). A social- belonging intervention improves STEM outcomes for students who speak English as a second language. Science Advances, 6(40), eabb6543. https://doi.org/10.1126/sciadv.abb6543.

Lakey, B., \& Cohen, S. (2000). Social support theory and measurement. In S. Cohen, L. G. Underwood, \& B. H. Gottlieb (Eds.), Social support theory and measurement (pp. 29- 52). Oxford University Press. https://www.oxfordclinicalpsych.com/view/10.1093/med:psych/9780195126709.001.0001/ med-9780195126709-chapter-2. Accessed 14 Mar 2021

Lee, S. J., \& Kim, Y. (2015). Searching for the meaning of community well-being. In S. J. Lee, Y. Kim, \& R. Phillips (Eds.), Community well-being and community development: Conceptions and applications (pp. 9-23). Springer International Publishing. https://doi.org/10.1007/978-3-319-12421-6_2.

Lee, S. J., Kim, Y., \& Phillips, R. (2015). Exploring the intersection of community well-being and community development. In S. J. Lee, Y. Kim, \& R. Phillips (Eds.), Community well-being and community development: Conceptions and applications (pp. 1-7). Springer International Publishing. https:// doi.org/10.1007/978-3-319-12421-6_1.

Lester, S. W., Standifer, R. L., Schultz, N. J., \& Windsor, J. M. (2012). Actual versus perceived generational differences at work: An empirical examination. Journal of Leadership \& Organizational Studies, 19(3), 341-354. https://doi.org/10.1177/1548051812442747.

Lyubomirsky, S., King, L., \& Diener, E. (2005). The benefits of frequent positive affect: Does happiness lead to success? Psychological Bulletin, 131(6), 803-855. https://doi.org/10.1037/0033-2909.131.6. 803 .

Mattison, E., \& Aber, M. S. (2007). Closing the achievement gap: The association of racial climate with achievement and behavioral outcomes. American Journal of Community Psychology, 40(1-2), 1-12. https://doi.org/10.1007/s10464-007-9128-x.

Mayhew, M. J., Rockenbach, A. N., Bowman, N. A., Seifert, T. A. D., Wolniak, G. C., Pascarella, E. T., \& Terenzini, P. T. (2016). How college affects students: 21 st century evidence that higher education works (Volume 3 edition). Jossey-Bass.

McDonald, M. J., Wong, P. T. R., \& Gingras, D. T. (2012). Meaning-in-life measures and development of a brief version of the personal meaning profile. In The human quest for meaning: Theories, research, and applications, 2nd ed (pp. 357-382). Routledge/Taylor \& Francis Group.

McKnight, P. E., \& Kashdan, T. B. (2009). Purpose in life as a system that creates and sustains health and well-being: An integrative, testable theory. Review of General Psychology, 13(3), 242-251. https:// doi.org/10.1037/a0017152.

Montoya, R. M., Purvin, D. M., Pittinsky, T. L., \& Rosenthal, S. A. (2007). National leadership index 2007: A national study of confidence in leadership. https://dspace.mit.edu/handle/1721.1/ 55720. Accessed 18 Apr 2021.

Morselli, P. L. (2000). Present and future role of mental illness advocacy associations in the management of the mentally ill: Realities, needs and hopes at the edge of the third millennium. Bipolar Disorders, 2(3 Pt 2), 294-300. https://doi.org/10.1034/j.1399-5618.2000.20310.x.

Okonofua, J. A., Paunesku, D., \& Walton, G. M. (2016). Brief intervention to encourage empathic discipline cuts suspension rates in half among adolescents. Proceedings of the National Academy of Sciences, 113(19), 5221-5226. https://doi.org/10.1073/pnas.1523698113.

Oman, D., Thoresen, C. E., \& McMahon, K. (1999). Volunteerism and mortality among the communitydwelling elderly. Journal of Health Psychology, 4(3), 301-316. https://doi.org/10.1177/1359105399 00400301.

Paunesku, D., Walton, G. M., Romero, C., Smith, E. N., Yeager, D. S., \& Dweck, C. S. (2015). Mind-set interventions are a scalable treatment for academic underachievement. Psychological Science, 26(6), 784-793. https://doi.org/10.1177/0956797615571017.

Pew Research Center. (2015, September 3). The whys and hows of generations research. Pew Research Center - U.S. Politics \& Policy. https://www.pewresearch.org/politics/2015/09/03/the-whys-andhows-of-generations-research/. Accessed 18 Jan 2021

Seemiller, C., \& Grace, M. (2016). Generation Z goes to college. John Wiley \& Sons.

Steger, M., \& Kashdan, T. (2013). The unbearable lightness of meaning: Well-being and unstable meaning in life. The Journal of Positive Psychology, 8, 103-115. https://doi.org/10.1080/17439760.2013. 771208.

Strauss, W., \& Howe, N. (1991). Generations: The history of America's future, 1584 to 2069. Morrow. 
Sung, H., \& Phillips, R. G. (2018). Indicators and community well-being: Exploring a relational framework. International Journal of Community Well-Being, 1(1), 63-79. https://doi.org/10.1007/ s42413-018-0006-0.

Tay, L., \& Kuykendall, L. (2013). Promoting happiness: The malleability of individual and societal subjective wellbeing. International Journal of Psychology, 48(3), 159-176. https://doi.org/10.1080/ 00207594.2013 .779379$.

Tinto, V. (1993). Leaving college: Rethinking the causes and cures of student attrition (2nd ed.). University of Chicago Press.

Verdín, D., Godwin, A., Kirn, A., Benson, L., \& Potvin, G. (2018). Understanding how engineering identity and belongingness predict grit for first-generation college students. School of Engineering Education Graduate Student Series. https://docs.lib.purdue.edu/enegs/75. Accessed 15 Mar 2021.

Vieno, A., Perkins, D. D., Smith, T. M., \& Santinello, M. (2005). Democratic school climate and sense of community in school: A multilevel analysis. American Journal of Community Psychology, 36(3), 327-341. https://doi.org/10.1007/s10464-005-8629-8.

World Health Organization. (2003). Advocacy for mental health. World Health Organization, Department of Mental Health and Substance Abuse, Geneva. https://www.who.int/mental_health/policy/servi ces/essentialpackage1v7/en/. Accessed 2 Mar 2021.

World Health Organization. (2005a). Promoting mental health: Concepts, emerging evidence, practice. (A WHO Report in Collaboration with the Victoria Health Promotion Foundation and the University of Melbourne.). World Health Organization. https://apps.who.int/iris/handle/10665/42940. Accessed 2 Mar 2021.

World Health Organization. (2005b). Constitution of the world health organization: Amendments to articles 24 and 25, adopted by the fifty-first World Health Assembly at Geneva May 16, 1998. U.S. Dept. of State. Retrieved from https://apps.who.int/gb/bd/PDF/bd47/EN/constitution-en.pdf?ua=1

Yeager, D. S., Henderson, M. D., D’Mello, S., Paunesku, D., Walton, G. M., Spitzer, B. J., \& Duckworth, A. L. (2014). Boring but important: A self-transcendent purpose for learning fosters academic selfregulation. Journal of Personality and Social Psychology, 107(4), 559-580. https://doi.org/10.1037/ a0037637.

Yeager, D. S., Walton, G. M., Brady, S. T., Akcinar, E. N., Paunesku, D., Keane, L., Kamentz, D., Ritter, G., Duckworth, A. L., Urstein, R., Gomez, E. M., Markus, H. R., Cohen, G. L., \& Dweck, C. S. (2016). Teaching a lay theory before college narrows achievement gaps at scale. Proceedings of the National Academy of Sciences of the United States of America, 113(24), E3341-E3348. https://doi. org/10.1073/pnas.1524360113.

Publisher's Note Springer Nature remains neutral with regard to jurisdictional claims in published maps and institutional affiliations. 